Supporting Information

for

\title{
Self-Assembly Dynamics of a Cylindrical Capsule Monitored by Fluorescence \\ Resonance Energy Transfer
}

Elizabeth S. Barrett, Trevor J. Dale, and Julius Rebek, Jr.*

The Skaggs Institute for Chemical Biology and Department of Chemistry, The Scripps Research Institute, MB-26, 10550 North Torrey Pines Road, La Jolla, California 92037

Email: jrebek@scripps.edu

\section{Absorption and Emission Spectra}

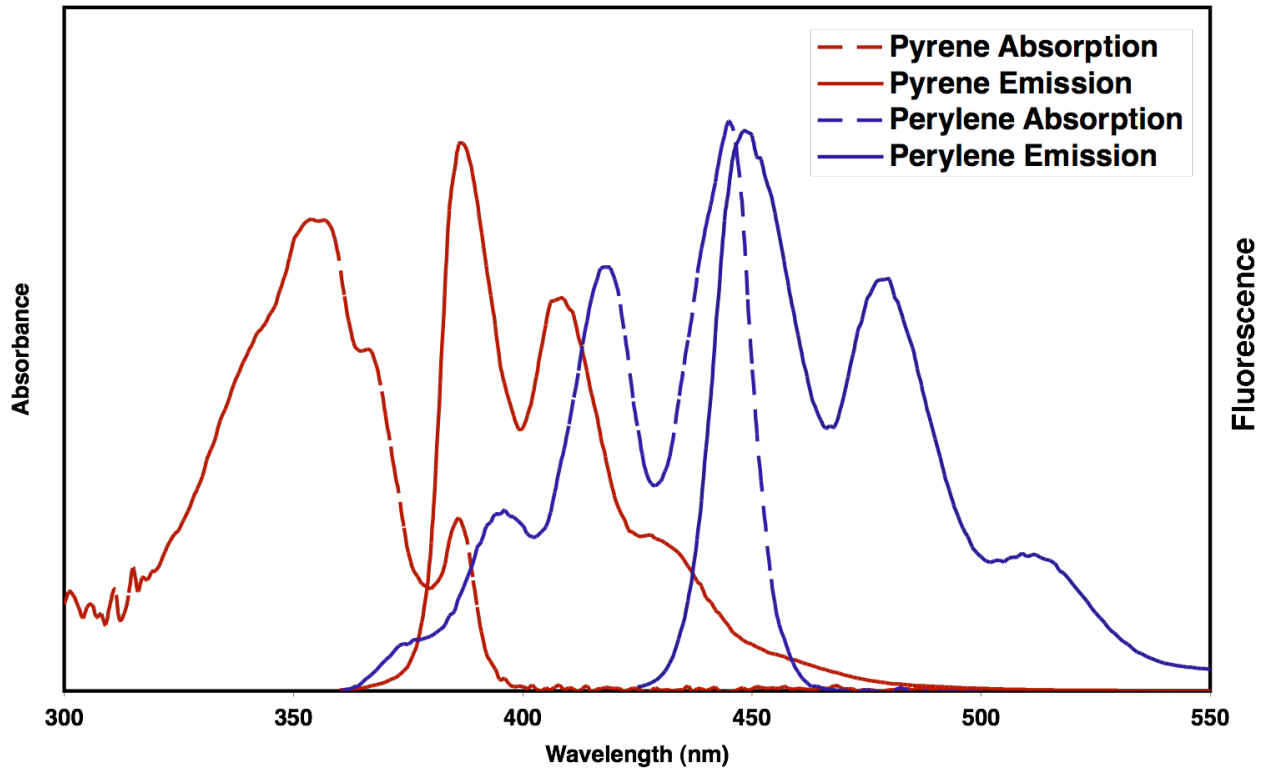

Figure S1: Absorption and emission spectra of the Pyrene and Perylene TBS protected resorcinarenes 3 and 6 in mesitylene. Excitation wavelength $=350 \mathrm{~nm}$.

\section{Titration of the Cylindrical Capsule with Methanol}

Shown in Figure S2 are the fluorescence emission spectra of the mixed pyrene and perylene capsules recorded with increasing amounts of methanol. A decrease in FRET is observed with an increase in methanol as the cylindrical capsule is reduced to its constituent cavitand monomers. The inherent sensitivities of the pyrene capsule 5.5 (D) and the perylene capsule 8.8 (A) to methanol were determined in control experiments. An increase in fluorescence was observed for each of the individual capsules 5.5 (D) and 8.8 
(A) when up to $3 \%$ methanol is added, these are shown in Figures S3 and S4. This accounts for the low decrease in the acceptor emission observed in Figure S2.

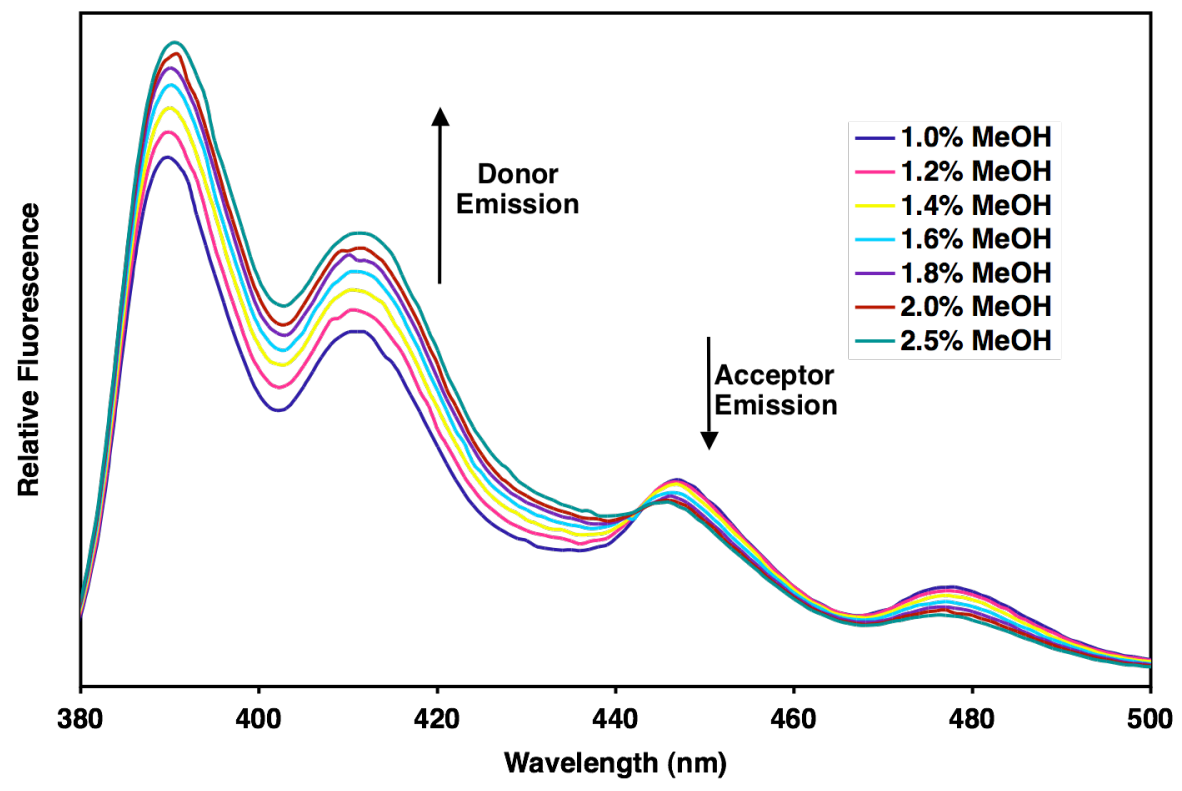

Figure S2. Emission spectra of the titration of the mixed capsule solution in toluene with methanol. Excitation wavelength $=350 \mathrm{~nm}$. 


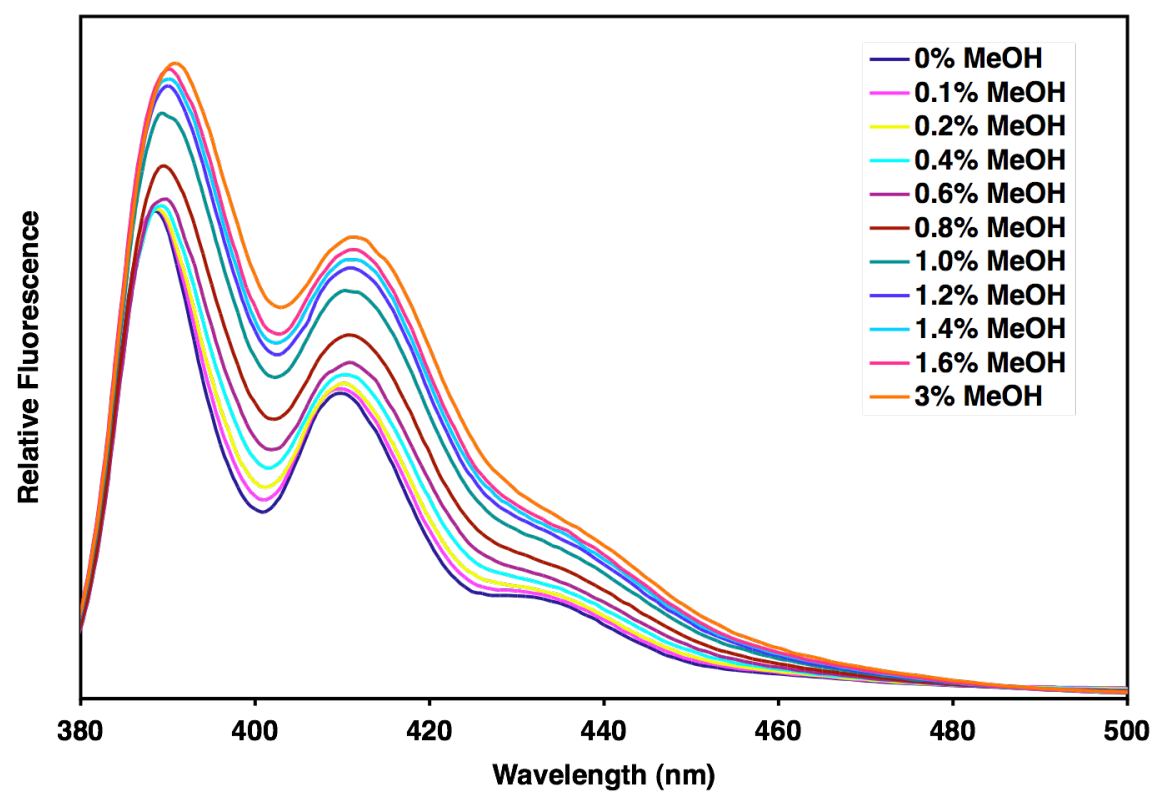

Figure S3. Emission spectra of the titration of the pyrene capsule solution $\mathbf{5 . 5}(\mathbf{D})$ in toluene with methanol. Excitation wavelength $=350 \mathrm{~nm}$.

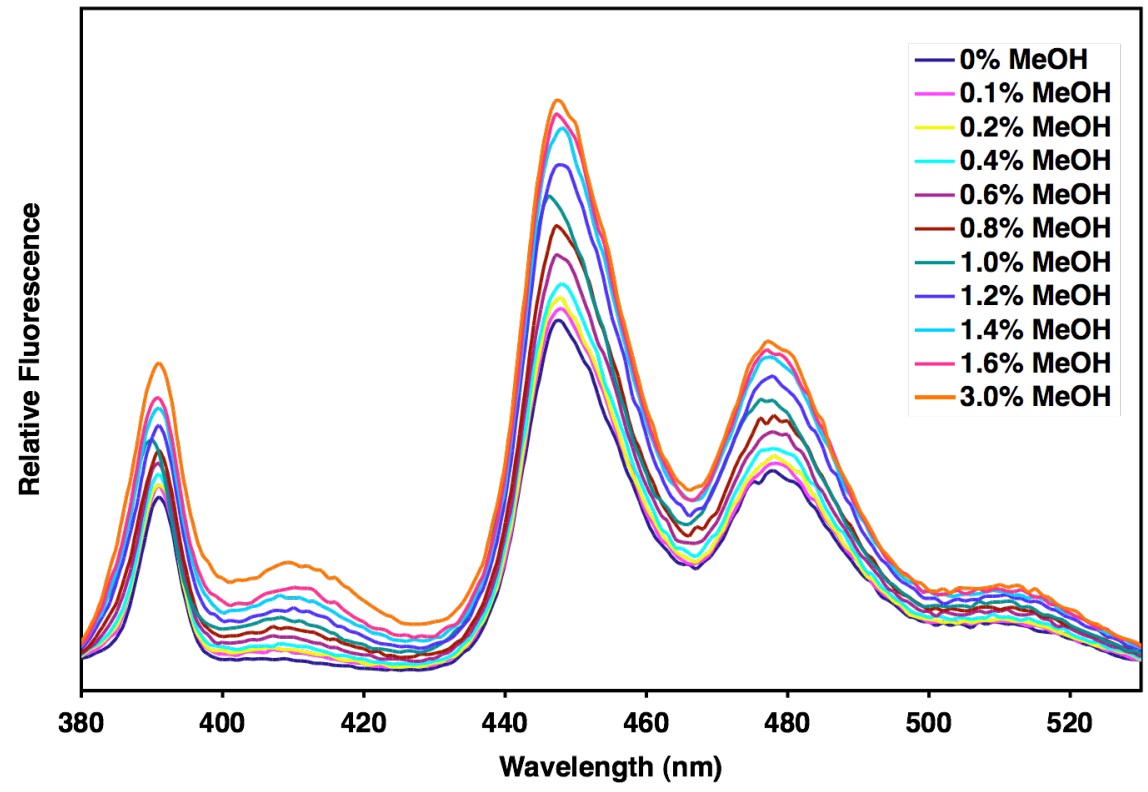

Figure S4. Emission spectra of the titration of the perylene capsule solution 8.8 (A) in toluene with methanol. Excitation wavelength $=350 \mathrm{~nm}$. 